\title{
Prenatal mercury exposure and infant birth weight in the Norwegian Mother and Child Cohort Study
}

\author{
Kristine Vejrup ${ }^{1, *}$, Anne Lise Brantsæeter ${ }^{2}$, Helle K Knutsen ${ }^{2}$, Per Magnus ${ }^{1}$, \\ Jan Alexander ${ }^{3}$, Helen E Kvalem ${ }^{2,4}$, Helle M Meltzer ${ }^{2}$ and Margaretha Haugen ${ }^{2}$ \\ 'Division of Epidemiology, Norwegian Institute of Public Health, Post Box 4404 Nydalen, NO-0403 Oslo, \\ Norway: ${ }^{2}$ Division of Environmental Medicine, Norwegian Institute of Public Health, Oslo, Norway: ${ }^{3}$ Office of \\ Director-General, Norwegian Institute of Public Health, Oslo, Norway: ${ }^{4}$ Biørknes College, Oslo, Norway
}

Submitted 21 January 2013: Final revision received 6 August 2013: Accepted 14 August 2013: First published online 80 October 2013

\begin{abstract}
Objective: To examine the association between calculated maternal dietary exposure to $\mathrm{Hg}$ in pregnancy and infant birth weight in the Norwegian Mother and Child Cohort Study (MoBa).

Design: Exposure was calculated with use of a constructed database of $\mathrm{Hg}$ in food items and reported dietary intake during pregnancy. Multivariable regression models were used to explore the association between maternal $\mathrm{Hg}$ exposure and infant birth weight, and to model associations with small-for-gestational-age offspring. Setting: The study is based on data from MoBa.

Subjects: The study sample consisted of 62941 women who answered a validated FFQ which covered the habitual diet during the first five months of pregnancy. Results: Median exposure to $\mathrm{Hg}$ was $0 \cdot 15 \mu \mathrm{g} / \mathrm{kg}$ body weight per week and the contribution from seafood intake was $88 \%$ of total $\mathrm{Hg}$ exposure. Women in the highest quintile compared with the lowest quintile of $\mathrm{Hg}$ exposure delivered offspring with $34 \mathrm{~g}$ lower birth weight (95\% CI $-46 \mathrm{~g},-22 \mathrm{~g}$ ) and had an increased risk of giving birth to small-for-gestational-age offspring, adjusted $\mathrm{OR}=1 \cdot 19(95 \% \mathrm{CI} 1 \cdot 08,1 \cdot 30)$. Although seafood intake was positively associated with increased birth weight, stratified analyses showed negative associations between $\mathrm{Hg}$ exposure and birth weight within strata of seafood intake.

Conclusions: Although seafood intake in pregnancy is positively associated with birth weight, $\mathrm{Hg}$ exposure is negatively associated with birth weight. Seafood consumption during pregnancy should not be avoided, but clarification is needed to identify at what level of $\mathrm{Hg}$ exposure this risk might exceed the benefits of seafood.
\end{abstract}

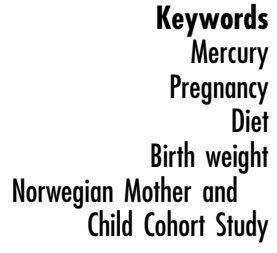

Environmental exposure to $\mathrm{Hg}$ is a recognised public health hazard. $\mathrm{Hg}$ is a well-known neurotoxicant and exposure can cause adverse effects to the nervous system, the developing brain being particularly vulnerable ${ }^{(1-3)}$. Hence, fetuses, infants and young children are especially susceptible to the toxic effects. $\mathrm{Hg}$ is formed mainly by bacterial methylation of inorganic mercury ( $\mathrm{IHg}$ ) into the organic form methylmercury $(\mathrm{MeHg})^{(4)}$. This transformation occurs in aquatic sediments with bioaccumulation in the food web. Fish and other seafood contain the highest concentrations of $\mathrm{Hg}$, with only small amounts in other food groups ${ }^{(5,6)}$. Total mercury $(\mathrm{THg})$ concentration in whole blood reflects exposure mainly to $\mathrm{Hg}$ in fish-eating populations $^{(7)}$ and has been shown to be directly correlated to the intake of fish and seafood ${ }^{(8)}$. The $\mathrm{Hg}$ concentration in fish and shellfish species ranges from $<0 \cdot 1 \mu \mathrm{g} / \mathrm{kg}$ for shellfish, such as oysters and mussels, to several $\mathrm{mg} / \mathrm{kg}$ reported in high-end predatory fish. These include ocean species like tuna, shark, swordfish and halibut, and freshwater species like pike, perch and brown trout ${ }^{(9)}$. Consequently, $\mathrm{Hg}$ exposure depends on the species of fish consumed as well as the frequency and quantity eaten. $\mathrm{Hg}$ in blood has an average half-life of $70 \mathrm{~d}$ in man, implicating that changing the diet could reduce the body burden of $\mathrm{Hg}$ within some months ${ }^{(10,11)}$. Seafood intake during pregnancy is of special interest owing to the observed positive impact on birth weight and neurodevelopment of the child ${ }^{(12-14)}$. Dietary seafood is a rich source of protein, vitamins and the essential trace elements iodine and Se, and a predominant source of $n$-3 fatty acids which may play a role in optimum neurodevelopment of infants ${ }^{(15,16)}$. Birth weight is considered a marker of intra-uterine development, is a strong predictor of infant development and also is an indicator of adult health $^{(17)}$. Children born with low birth weight and children born preterm account for most of all neonatal 
mortality, as well as short-term and long-term morbidity $^{(18)}$. The prevalence of small for gestational age (SGA) in the Norwegian Mother and Child Cohort Study (MoBa) is $6.6 \%$ and the prevalence of low birth weight $(<2500 \mathrm{~g})$ is about $4.6 \%$ in the MoBa cohort and $0.7 \%$ in children born at term $(>37 \text { weeks of gestation })^{(19,20)}$. Positive associations between seafood consumption during pregnancy, and in particular lean seafood, and birth weight and SGA have been found in several studies, including the present cohort, while a few studies report inverse associations $^{(21,22)}$. These inverse associations are often connected to the presence of environmental toxicants like polychlorinated biphenyls (PCB) and $\mathrm{Hg}^{(23,24)}$. While most studies on prenatal $\mathrm{Hg}$ exposure and birth weight did not find any associations ${ }^{(25-27)}$, some recent studies suggest a negative association between $\mathrm{Hg}$ exposure and birth size ${ }^{(24,26)}$. In 2004 the US Federal government issued advice for pregnant women and women of childbearing age to restrict their consumption of seafood to $340 \mathrm{~g} /$ week to reduce fetal exposure to $\mathrm{Hg}$, while still providing enough $n$-3 fatty acids ${ }^{(28,29)}$. The relationship between the benefits and risks associated with fish and seafood consumption is an important issue.

Norway has one of the highest average intakes of fish and seafood in Europe ${ }^{(30)}$. However, consumption of seafood varies considerably and the seafood intake of pregnant women is lower than that in the general population $^{(31)}$. Pregnant women with no or a low consumption are therefore encouraged to eat fish during pregnancy. In $\mathrm{MoBa}$, a large, prospective pregnancy cohort, women answered a detailed FFQ in mid-pregnancy. The dietary data provide a unique opportunity to explore dietary exposures to a wide range of foods, nutrients and contaminants and to examine associations between maternal diet and health outcomes in the children ${ }^{(32)}$. The aims of the present study were: (i) to estimate the dietary exposure to $\mathrm{Hg}$ in $\mathrm{MoBa}$; and (ii) to examine if maternal dietary $\mathrm{Hg}$ exposure was associated with infant birth weight.

\section{Materials and methods}

\section{Population and study design}

The data set used in the present study is part of MoBa, initiated by and maintained at the Norwegian Institute of Public Health ${ }^{(20)}$. In brief, MoBa is a nationwide pregnancy cohort that in the years from 1999 to 2009 included 108000 pregnancies. Women were recruited to the study through a postal invitation in connection with their first routine ultrasound examination. The participation rate of invited pregnant women was approximately 38.5\%. Written informed consent was obtained from each participant. Pregnancy and birth records from the Medical Birth Registry of Norway (MBRN) are linked to the MoBa database ${ }^{(33)}$. The study was approved by the Regional
Committee for Ethics in Medical Research and the Data Inspectorate in Norway. The present study uses the quality-assured data files released for research in 2010 (version 5). The questionnaires used in the current study were completed in gestational weeks 15 (Q1) and gestational weeks 17-22 (Q2), and when the child was 6 months old $\left(\mathrm{Q}^{4}\right)^{(34)}$. Q2 is an FFQ, while Q1 and Q4 are general questionnaires covering mother and child health, lifestyles and background factors. In this data file 78744 women had answered questionnaires Q1, Q2 and Q4, and had singleton births recorded in MBRN. We excluded participants who had not recorded their weight prior to pregnancy ( $n$ 1722) and woman having an improbable energy intake, i.e. energy intake $<4.5 \mathrm{MJ}$ or $>20 \mathrm{MJ}$ ( $n$ 1238). All births with gestational age $\leq 37$ weeks and $>43$ weeks were excluded ( $n$ 3730). Data on newborns with reported birth weight lower than $600 \mathrm{~g}$ ( $n$ 39) were examined and were considered obvious data transfer errors, i.e. the children were recorded with normal birth length and head circumference. Finally we excluded participants with multiple participation in MoBa ( $n$ 9074), resulting in a final sample of 62941 participants for the present study. For the fully adjusted analyses 5953 women were excluded due to missing information on gestational weight gain, leaving 56988 mother-child pairs.

\section{Dietary information}

The MoBa FFQ (downloadable at http://www.fhi.no) was completed in weeks $17-22$ of gestation. The dietary data used in the present study were collected from February 2002 to November 2009. The FFQ is a semi-quantitative questionnaire designed to capture dietary habits and intake of dietary supplements during the first four to five months of pregnancy ${ }^{(32)}$. The FFQ included questions about intake of 255 food items with special emphasis on various fish and seafood items. There were ten questions about cold cuts and spreads made from fish and shellfish, and sixteen questions about fish or shellfish eaten for dinner. FoodCalc ${ }^{(35)}$ and the Norwegian food composition table ${ }^{(36)}$ were used to calculate food and nutrient intakes. The FFQ has been extensively validated in a MoBa sub-population ( $n$ 119) using a $4 \mathrm{~d}$ weighed food diary and biological markers in blood and urine as reference measures ${ }^{(37)}$. The validation study showed that the MoBa FFQ is a valid instrument for assessing habitual diet during the first four to five months of pregnancy. Median seafood intake by the FFQ and the food diary were $39 \cdot 2$ and $30 \cdot 4 \mathrm{~g} / \mathrm{d}$ respectively and the correlation was 0.37 (95\% CI 0.20, 0.52). Furthermore, seafood intake by the two methods was reflected by blood concentrations of $\mathrm{THg}$, arsenic, Se and erythrocyte $\mathrm{DHA}^{(38)}$.

\section{Calculation of total Hg exposure}

A database on THg concentrations in Norwegian food, including fish and other seafood items, was established and has been described in detail by Jenssen et $a l^{(39)}$. 
In their study in a non-pregnant population, the estimated $\mathrm{Hg}$ exposure from diet was strongly reflected by blood THg levels. The database consists of THg concentrations in marine and freshwater fish and shellfish compiled mainly from Norwegian samples. Samples expected to be impacted by local pollution sources (i.e. from areas with known point sources) were excluded. For each species of fish or other seafood, the mean THg concentration was estimated by averaging the means. When the mean value was not available, the reported median concentrations were used. THg values in other food items were collected from other Scandinavian countries when Norwegian analyses were not available. Lower-bound concentrations (values less than levels of quantification are set to zero) in this database were used to calculate the dietary exposure to $\mathrm{Hg}$ at the individual level for the MoBa participants. Comparison of the estimated dietary $\mathrm{Hg}$ exposure against blood levels of THg in the MoBa validation study sample (Spearman correlation $r=0 \cdot 24 ; 95 \%$ CI 0 06, 0 40) and in a national population sample of men and women with a large range of seafood consumption $(r=0 \cdot 46$; 95\% CI $0.35,0.57)$ showed that the dietary $\mathrm{Hg}$ estimate will correctly distinguish between individuals with high and low $\mathrm{Hg}$ exposure ${ }^{(39)}$. Contribution of $\mathrm{Hg}$ from different types of food groups and subgroups of seafood is presented as micrograms per day $(\mu \mathrm{g} / \mathrm{d})$, and the estimated dietary intake of $\mathrm{Hg}$ is presented as micrograms per kilogram of body weight (BW) per week $(\mu \mathrm{g} / \mathrm{kg} \mathrm{BW}$ per week) ranked into quintiles. The $\mathrm{Hg}$ exposure was categorized into quintiles to ensure power for the regression analysis.

\section{Definitions of fish and seafood variables}

Total seafood describes the combined reported intake of all fish and other seafood items. Fish intake was also examined according to lean and oily species. Lean fish comprised reported intakes of fillets of cod, saithe, haddock, pollock, halibut, plaice, flounder, tuna, perch, pike, catfish and fish roe, all items of lean fish eaten as bread spread, and lean fish in mixed dishes as fish fingers or fish au gratin. Oily fish included intake of salmon, trout, mackerel and herring, both as dinner fillets and as bread spreads. Shellfish comprised intake of shrimps, crab and mussels. In an attempt to disentangle the risk-benefit of fish and seafood intake $v$. Hg exposure, we stratified the total seafood intake by quartiles. The quartiles for fish intake were corresponding to approximate weekly consumption categories: the first quartile $(0-19 \cdot 0 \mathrm{~g} / \mathrm{d})$ corresponds to $<1$ portion/week, the second quartile $(19 \cdot 1-30 \cdot 9 \mathrm{~g} / \mathrm{d})$ to $\sim 1.5$ portions/week, the third quartile $(31 \cdot 0-44 \cdot 9 \mathrm{~g} / \mathrm{d})$ to $\sim 1 \cdot 5-2$ portions/week and the fourth quartile $(\geq 45 \cdot 0 \mathrm{~g} / \mathrm{d})$ corresponds to $>2$ portions/week.

\section{Birtb weight}

Birth weight was measured by a midwife at birth and reported to $\mathrm{MBRN}^{(33)}$. Data from MBRN also included information on pregnancy duration. Pregnancy duration based on ultrasound was available for $98.2 \%$ of the women, and if ultrasound information was missing, gestational age was based on the last menstrual period. Only pregnancies with duration of 37-42 weeks were included in the analysis. SGA is defined as infants with birth weight below the 10th percentile, at the attained gestational age, in the general population ${ }^{(40)}$.

\section{Otber variables}

Potential confounding variables were chosen on the basis of previous knowledge and included maternal age, height, BMI, parity, education, smoking, gestational weight gain, pregnancy duration in weeks, total energy intake, and long-chain $n$ - 3 fatty acids from the diet and food supplements. Self-reported pre-pregnancy height and weight were used to calculate BMI $\left(\mathrm{kg} / \mathrm{m}^{2}\right)$. BMI was divided into the WHO categories $(<18 \cdot 5$, $18 \cdot 5-24 \cdot 9, \quad 25 \cdot 0-29 \cdot 9, \quad 30 \cdot 0-34 \cdot 9$ and $\left.\geq 35 \cdot 0 \mathrm{~kg} / \mathrm{m}^{2}\right)$. Maternal educational attainment was divided into three categories ( $\leq 12,13-16$ and $\geq 17$ years) and firsttrimester smoking into three categories (non-smoker, occasional smoker and daily smoker). Maternal age at delivery was retrieved from MBRN and used as a continuous variable except for descriptive purpose. Parity was based on data from both MoBa and MBRN, and categorised into the numbers of previous pregnancies of $>22$ weeks' duration. Missing values for pre-pregnant BMI and maternal education were grouped as a 'missing data' category. For calculations of long-chain n-3 fatty acids intake from food we used data from the Norwegian food composition table, and for intake from supplements we used data from a database including more than 1000 different dietary supplements with nutrient content per portion ${ }^{(41)}$.

\section{Statistical metbods}

The estimated dietary $\mathrm{Hg}$ exposure as well as food consumption data were not normally distributed. Medians and percentiles were used for unadjusted analyses. Multivariable linear regression models were used to explore the association between maternal $\mathrm{Hg}$ exposure and infant birth weight. Multivariable logistic regression was used to the model association between maternal $\mathrm{Hg}$ exposure and the risk of delivering SGA offspring. Relative risks were approximated by odds ratios. The following variables were included in the adjusted models: maternal age at delivery, height, pre-pregnant BMI, parity, education, smoking in pregnancy, gestational weight gain, total energy intake and intake of $n-3$ fatty acids. Intake of $n-3$ fatty acids was modelled both as a categorical variable and on a continuous scale in the analysis. Because of the high co-linearity between seafood consumption and dietary $\mathrm{Hg}$ exposure, we stratified the results from the multiple regression analyses by quartiles of seafood intake. All models were checked for 
residual normality. The analyses were performed using the statistical software package PASW Statistics 17 and $P<0 \cdot 05$ was considered significant.

\section{Results}

The estimated median (5th-95th percentile) dietary $\mathrm{Hg}$ exposure was $1.45(0.31-3.41) \mu \mathrm{g} / \mathrm{d}$, corresponding to a daily $\mathrm{Hg}$ exposure of $0.02(0 \cdot 00-0 \cdot 05) \mu \mathrm{g} / \mathrm{kg} \mathrm{BW}$ and a weekly $\mathrm{Hg}$ exposure of $0 \cdot 15(0 \cdot 03-0 \cdot 38) \mu \mathrm{g} / \mathrm{kg} \mathrm{BW}$. Fish and seafood were the main source of $\mathrm{Hg}$ exposure accounting for $88 \%$ of the intake of $\mathrm{Hg}$ in diet. The contribution of $\mathrm{Hg}$ from different types of seafood and fish products showed that approximately $52 \%$ came from lean fish, $27 \%$ from oily fish and 9\% from shellfish and fish products. Eggs and cereals were the main non-fish sources, contributing $9 \%$ of the total intake of $\mathrm{Hg}$. Other food groups which contained $\mathrm{Hg}$ were fruit and vegetables, sweets and chocolate and meat (Table 1). The maternal characteristics of the study population showed that the estimated exposure to $\mathrm{Hg}$ from diet increased with increasing maternal age, length of education, energy intake and amount of seafood eaten (Table 2). The estimated $\mathrm{Hg}$ exposure was higher among women with a normal and low BMI than among overweight woman, and higher among non-smokers than among smokers. The mean birth weight of the offspring in the present study was 3587 (SD 560) g. In the adjusted multivariable linear regression model with birth weight as outcome, women in the highest quintile of $\mathrm{Hg}$ exposure delivered babies with on average $34 \mathrm{~g}$ (95\% CI $-46 \mathrm{~g},-22 \mathrm{~g}$ ) lower birth weight than women in the lowest quintile of $\mathrm{Hg}$ exposure (Table 3). In the logistic regression analysis with SGA as the outcome, no association with $\mathrm{Hg}$ exposure was seen for women in the second to fourth quintiles of $\mathrm{Hg}$ exposure compared with the lowest quintile, while a significantly increased risk of SGA was observed for women in the highest quintile with an adjusted OR of $1 \cdot 19$ (95\% CI 1·08, 1·30; Table 4).
We used beta values (unstandardized), obtained from analyses stratified by seafood consumption, to plot expected birth weight by increasing $\mathrm{Hg}$ exposure (Fig. 1). The plot shows a reduction in birth weight with increasing $\mathrm{Hg}$ exposure in all strata of seafood intake. The statistical power in the two groups of highest $\mathrm{Hg}$ exposure/lowest seafood intake and lowest $\mathrm{Hg}$ exposure/highest seafood intake was low and not presented in Fig. 1. We saw a tendency of a similar pattern for SGA when we stratified by seafood consumption and plotted SGA by increasing $\mathrm{Hg}$ exposure (data not shown). In the first quartile of seafood intake there was no linear association found between $\mathrm{Hg}$ exposure and SGA. Hg exposure was significantly associated with SGA in the second and third quartile of seafood intake. In the fourth quartile the analysis collapsed due to the low number of SGA cases.

The bivariate correlation coefficient between $\mathrm{Hg}$ exposure and long-chain $n$-3 fatty acid intake was $0 \cdot 49$, which can justify the inclusion of this variable as a confounder in the models. The relatively modest correlation can be explained by the pregnant women's frequent use of long-chain $n$-3 fatty acid supplements; as many as $67 \%$ of the women reported use of some sort of $n-3$ supplementation like cod-liver oil. We did the same regression analysis for long-chain $n$-3 fatty acids as for $\mathrm{Hg}$ by dividing the exposure into quartiles, and found no differences in the stratified analysis. We also included long-chain $n$ - 3 fatty acids as a continuous variable in the regression model, and no significant impact was found on birth weight.

\section{Discussion}

Although the large majority of the participants did not have a calculated dietary exposure exceeding the Provisional Tolerable Weekly Intake (PTWI) of $1.6 \mu \mathrm{g}$ $\mathrm{MeHg} / \mathrm{kg}$ BW per week recently established by the Joint FAO/WHO Expert Committee on Food Additives ${ }^{(42)}$, the current population-based study showed that maternal

Table 1 Estimated consumption of food groups contributing to dietary total mercury (THg) exposure, estimated calculated THg exposure $(\mu \mathrm{g} / \mathrm{d})$ and mean $(\%)$ contribution to THg exposure in pregnant Norwegian women, the Norwegian Mother and Child Cohort Study, 2002-2009. Total seafood is divided into subgroups

\begin{tabular}{|c|c|c|c|c|c|}
\hline \multirow[b]{2}{*}{ Food group } & \multicolumn{2}{|c|}{ Food consumed $(\mathrm{g} / \mathrm{d})$} & \multicolumn{3}{|c|}{$\mathrm{THg}(\mu \mathrm{g} / \mathrm{d})$} \\
\hline & Median & P5-P95 & Median & P5-P95 & $\%$ \\
\hline Total seafood & 31 & $5-74$ & $1 \cdot 12$ & $0 \cdot 8-3 \cdot 03$ & 88 \\
\hline Lean fish & 19 & $1-46$ & 0.65 & $0.002-1 \cdot 84$ & 52 \\
\hline Oily fish & 6 & $0-33$ & $0 \cdot 25$ & $0-1 \cdot 31$ & 27 \\
\hline Shellfish & 3 & $0-13$ & 0.07 & $0-0.51$ & 9 \\
\hline Meat products & 89 & $42-310$ & 0.00 & $0-0.0058$ & $<1$ \\
\hline Chocolate and sweets & 35 & $6-120$ & 0.01 & $0.004-0.025$ & 1 \\
\hline Fruit and vegetables & 380 & $130-875$ & 0.01 & $0-0.054$ & 1 \\
\hline Egg & 10 & $3-40$ & 0.04 & $0 \cdot 02-0 \cdot 12$ & 3 \\
\hline Cereals & 283 & $125-496$ & 0.08 & $0.02-0.23$ & 6 \\
\hline
\end{tabular}

P5, 5th percentile; P95, 95th percentile. 
Table 2 Estimated dietary mercury intake during pregnancy according to maternal characteristics, the Norwegian Mother and Child Cohort Study, 2002-2009

\begin{tabular}{|c|c|c|c|c|}
\hline & \multirow[b]{2}{*}{$n$} & \multirow[b]{2}{*}{$\%$} & \multicolumn{2}{|c|}{$\mathrm{Hg}(\mu \mathrm{g} / \mathrm{kg}$ BW per week) } \\
\hline & & & Median & P5-P95 \\
\hline All & 62941 & 100 & $0 \cdot 15$ & $0 \cdot 03-0.38$ \\
\hline \multicolumn{5}{|l|}{ Maternal age at delivery } \\
\hline$<25$ years & 7206 & $11 \cdot 4$ & $0 \cdot 13$ & $0 \cdot 02-0 \cdot 38$ \\
\hline $25-29$ years & 21368 & 33.9 & $0 \cdot 14$ & $0.03-0.37$ \\
\hline $30-34$ years & 26855 & $42 \cdot 7$ & $0 \cdot 16$ & $0.04-0.38$ \\
\hline$\geq 35$ years & 7512 & 11.9 & $0 \cdot 17$ & $0.05-0.40$ \\
\hline$P$ value & & & $<0.001$ & \\
\hline \multicolumn{5}{|c|}{ Pre-pregnancy $\mathrm{BMI}\left(\mathrm{kg} / \mathrm{m}^{2}\right)$} \\
\hline$<18.5$ & 1838 & $2 \cdot 9$ & $0 \cdot 21$ & $0.04-0.54$ \\
\hline $18 \cdot 5-24 \cdot 9$ & 41333 & $65 \cdot 7$ & $0 \cdot 17$ & $0.04-0.40$ \\
\hline $25 \cdot 0-29 \cdot 9$ & 13624 & $21 \cdot 6$ & $0 \cdot 13$ & $0.03-0.31$ \\
\hline $30 \cdot 0-34 \cdot 9$ & 4277 & $6 \cdot 8$ & $0 \cdot 11$ & $0.02-0.26$ \\
\hline$\geq 35 \cdot 0$ & 1605 & $2 \cdot 6$ & 0.09 & $0.02-0.23$ \\
\hline$P$ value & & & $<0.001$ & \\
\hline Missing & 264 & 0.4 & 0.14 & $0.02-0.44$ \\
\hline \multicolumn{5}{|l|}{ Maternal education } \\
\hline$\leq 12$ years & 19661 & $31 \cdot 2$ & $0 \cdot 14$ & $0.02-0.38$ \\
\hline $13-16$ years & 26333 & $41 \cdot 8$ & $0 \cdot 15$ & $0.04-0.36$ \\
\hline$\geq 17$ years & 15612 & $24 \cdot 8$ & $0 \cdot 17$ & $0.05-0.40$ \\
\hline$P$ value & 1335 & $2 \cdot 1$ & $<0.001$ & \\
\hline Missing & & & $0 \cdot 15$ & $0.02-0.40$ \\
\hline \multicolumn{5}{|l|}{ Parity } \\
\hline First child & 32645 & 51.9 & $0 \cdot 15$ & $0.03-0.38$ \\
\hline Second child & 19534 & $31 \cdot 1$ & $0 \cdot 15$ & $0.03-0.37$ \\
\hline Third child & 8673 & $13 \cdot 8$ & $0 \cdot 16$ & $0.04-0.37$ \\
\hline Fourth child or more & 2045 & $3 \cdot 3$ & $0 \cdot 16$ & $0.04-0.39$ \\
\hline$P$ value & & & $<0.001$ & \\
\hline \multicolumn{5}{|l|}{ Smoking in pregnancy } \\
\hline Non-smoker & 57439 & 91.9 & $0 \cdot 15$ & $0.03-0.38$ \\
\hline Occasional smoker & 1735 & $2 \cdot 8$ & $0 \cdot 15$ & $0.02-0.40$ \\
\hline Daily smoker & 3316 & $5 \cdot 3$ & 0.13 & $0.02-0.37$ \\
\hline$P$ value & & & $<0.001$ & \\
\hline \multicolumn{5}{|l|}{ Total seafood intake $(\mathrm{g} / \mathrm{d})$} \\
\hline Quartile $1(0-19 \cdot 0)$ & 15735 & $24 \cdot 9$ & 0.06 & $0 \cdot 01-0 \cdot 14$ \\
\hline Quartile $2(19 \cdot 1-30 \cdot 9)$ & 15735 & $24 \cdot 9$ & $0 \cdot 13$ & $0.07-0.23$ \\
\hline Quartile 3 (31.0-44.9) & 15736 & $24 \cdot 9$ & $0 \cdot 18$ & $0 \cdot 10-0.32$ \\
\hline Quartile $4(\geq 45.0 \mathrm{~g})$ & 15735 & $24 \cdot 9$ & 0.27 & $0.15-0.53$ \\
\hline$P$ value & & & $<0.001$ & \\
\hline \multicolumn{5}{|l|}{ Total energy intake $(\mathrm{MJ} / \mathrm{d})$} \\
\hline Quartile $1(4 \cdot 5-7 \cdot 8)$ & 15735 & $24 \cdot 9$ & $0 \cdot 13$ & $0.02-0.35$ \\
\hline Quartile $2(7 \cdot 9-9 \cdot 2)$ & 15735 & $24 \cdot 9$ & $0 \cdot 15$ & $0.03-0.36$ \\
\hline Quartile $3(9 \cdot 3-11 \cdot 1)$ & 15735 & $24 \cdot 9$ & $0 \cdot 16$ & $0.04-0.37$ \\
\hline Quartile $4(\geq 11 \cdot 2)$ & 15736 & $25 \cdot 3$ & $0 \cdot 17$ & $0.04-0.42$ \\
\hline$P$ value & & & $<0.001$ & \\
\hline
\end{tabular}

BW, body weight; P5, 5th percentile; P95, 95th percentile.

Less than $5 \%$ missing information on all covariates. $P$ value from regression of ranked $\mathrm{Hg}$.

Table 3 Associations between birth weight and estimated dietary mercury exposure in pregnant Norwegian women ( $n$ 62941), the Norwegian Mother and Child Cohort Study, 2002-2009

\begin{tabular}{|c|c|c|c|c|c|c|c|}
\hline \multirow[b]{2}{*}{ Total estimated $\mathrm{Hg}$ ( $\mu \mathrm{g} / \mathrm{kg} \mathrm{BW}$ per week) (range) } & \multirow[b]{2}{*}{$n$} & \multicolumn{3}{|c|}{ Unadjusted } & \multicolumn{3}{|c|}{ Adjusted $^{*}$} \\
\hline & & $\beta(g)$ & $95 \% \mathrm{Cl}$ & $P$ value & $\beta(\mathrm{g})$ & $95 \% \mathrm{Cl}$ & $P$ value \\
\hline Quintile $1(0.06-0.08)$ & 12606 & Referent & - & - & Referent & - & - \\
\hline Quintile $2(0.08-0.13)$ & 12573 & -1 & $-12,11$ & 0.91 & -2 & $-13,9$ & $0 \cdot 74$ \\
\hline Quintile $3(0 \cdot 13-0 \cdot 18)$ & 12584 & -5 & $-16,7$ & 0.45 & -1 & $-12,10$ & 0.92 \\
\hline Quintile $4(0 \cdot 18-0 \cdot 25)$ & 12602 & -29 & $-41,-17$ & 0.00 & -10 & $-22,1$ & 0.07 \\
\hline Quintile $5(0 \cdot 25-2 \cdot 29)$ & 12576 & -80 & $-92,-68$ & 0.00 & -34 & $-46,-22$ & 0.00 \\
\hline
\end{tabular}

BW, body weight.

$n 56998$ in the adjusted model because of missing data on gestational weight gain.

*Adjusted for energy intake, maternal age, pre-pregnancy BMI, parity, smoking during pregnancy, pregnancy duration in weeks, intake of $n$ - 3 fatty acids, maternal height, maternal education and gestational weight gain. 
Table 4 Associations between maternal dietary mercury exposure and risk of delivering a small-for-gestational-age-baby in pregnant Norwegian women ( $n 62$ 941), the Norwegian Mother and Child Cohort Study, 2002-2009

\begin{tabular}{|c|c|c|c|c|c|c|c|}
\hline \multirow[b]{2}{*}{ Total estimated $\mathrm{Hg}$ ( $\mu \mathrm{g} / \mathrm{kg} \mathrm{BW}$ per week) (range) } & \multirow[b]{2}{*}{$n$} & \multicolumn{3}{|c|}{ Unadjusted } & \multicolumn{3}{|c|}{ Adjusted $^{*}$} \\
\hline & & OR & $95 \% \mathrm{Cl}$ & $P$ value & OR & $95 \% \mathrm{Cl}$ & $P$ value \\
\hline Quintile $1(0.06-0.08)$ & 12606 & Referent & - & - & Referent & - & - \\
\hline Quintile $2(0 \cdot 08-0 \cdot 13)$ & 12573 & $1 \cdot 02$ & $0 \cdot 94,1 \cdot 11$ & $0 \cdot 60$ & $1 \cdot 05$ & $0 \cdot 96,1 \cdot 14$ & $0 \cdot 32$ \\
\hline Quintile $3(0 \cdot 13-0 \cdot 18)$ & 12584 & $1 \cdot 00$ & $0.92,1.09$ & 0.93 & $1 \cdot 00$ & $0.91,1.09$ & 0.92 \\
\hline Quintile $4(0.18-0.25)$ & 12602 & $1 \cdot 02$ & $0 \cdot 94,1 \cdot 11$ & 0.57 & $1 \cdot 00$ & $0.91,1.09$ & $0 \cdot 87$ \\
\hline Quintile $5(0 \cdot 25-2 \cdot 29)$ & 12576 & $1 \cdot 28$ & $1 \cdot 18,1 \cdot 38$ & 0.00 & $1 \cdot 19$ & $1 \cdot 08,1 \cdot 30$ & 0.00 \\
\hline
\end{tabular}

*Adjusted for energy intake, maternal age, pre-pregnancy BMI, parity, smoking during pregnancy, pregnancy duration in weeks, intake of $n$ - 3 fatty acids, maternal height, maternal education and gestational weight gain.

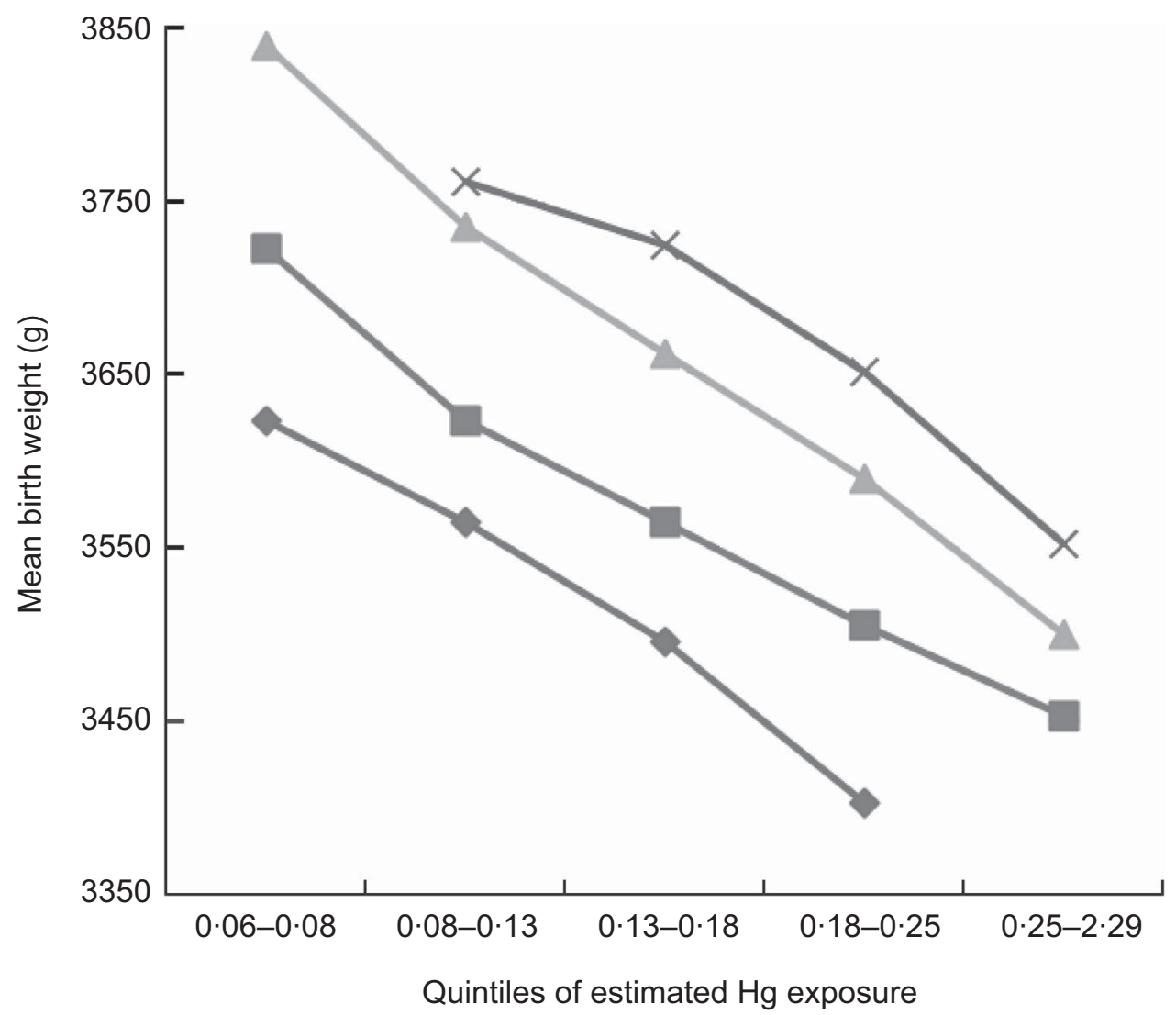

Fig. 1 Associations between maternal dietary mercury exposure (quintiles) and mean birth weight stratified by maternal seafood intake (quartiles*: —-, quartile 1, seafood intake $0-19 \mathrm{~g} / \mathrm{d}$; -- , quartile 2 , seafood intake $19-31 \mathrm{~g} / \mathrm{d}$; - , quartile 3, seafood intake $31-45 \mathrm{~g} / \mathrm{d}$; $-\leftarrow$, quartile 4 , seafood intake $45-350 \mathrm{~g} / \mathrm{d}$ ) in the Norwegian Mother and Child Cohort Study, $2002-2009$. ${ }^{*}$ Adjusted for energy intake. $P$ for trend across increasing mercury exposure in all quartiles of seafood intake: $<0 \cdot 001$. Data points for the lowest quintile of mercury exposure in the upper quartile of seafood intake $(n 10)$ and for highest quintile of mercury exposure in the lowest quartile of seafood intake $(n 39)$ are not shown due to low statistical power

dietary $\mathrm{Hg}$ exposure had a significant negative association with the birth weight of offspring, with those in the highest exposure group having an increased risk of giving birth to babies being SGA. These findings are remarkable taking into account that $\mathrm{Hg}$ exposure also in the highest quintile is generally below the European Food Safety Authority's Tolerable Weekly Intake (TWI). Only ten women of the cohort exceeded the PTWI of $1.6 \mu \mathrm{g} / \mathrm{kg}$ BW per week. A slightly higher proportion, 0•4\% ( $n$ 251) of the women, exceeded the reference dose (RfD) of $0 \cdot 1 \mu \mathrm{g} \mathrm{MeHg} / \mathrm{kg}$ BW per d set by the US Environmental Protection Agency ${ }^{(43)}$. However, as presented before for the present cohort and in agreement with other studies, maternal seafood consumption had an overall positive association with infant birth weight $\left(\right.$ Fig. 1) ${ }^{(21,22,31)}$. Hg exposure was strongly related to total seafood consumption with $88 \%$ of the estimated dietary $\mathrm{Hg}$ originating from seafood. 
Our findings of estimated levels of dietary $\mathrm{Hg}$ exposure are in agreement with what was found in a study of Swedish women of childbearing age, as well as similar to dietary exposure levels reported worldwide in women of childbearing age ${ }^{(44,45)}$. Studies of maternal Hg exposure and infant birth weight have until recently not reported significant associations ${ }^{(25,46,47)}$. Although studies have found associations between exposure to other environmental contaminants accumulating in fish and seafood and fetal growth ${ }^{(48,49)}$, it is only recently that reports of a direct adverse association to low-level $\mathrm{Hg}$ exposure have been published. A recent meta-analysis on fetal $\mathrm{Hg}$ exposure and birth outcome shows mixed results, but with some studies showing a negative association between low $\mathrm{Hg}$ exposure and fetal growth ${ }^{(50)}$. Hg easily crosses the placenta and disrupts many steps in brain development, which may indirectly lead to fetal growth restriction. $\mathrm{Hg}$ results in a non-optimal intra-uterine environment which could impair fetal growth, but the biological mechanism is not clear. A Korean study from 2010 suggested that interactions of $\mathrm{Hg}$ with glutathione $S$-transferase (GST) play a role in reducing birth weight. That study found that both cord blood $\mathrm{Hg}$ and maternal blood $\mathrm{Hg}$ were inversely related to birth weight, and specifically examined the association between GST polymorphisms in mothers, blood THg and infant birth weight ${ }^{(26)}$. Hg excretion rates vary widely among individuals and involve glutathione conjugation by GST $^{(51)}$. The results showed that the negative association with birth weight was stronger among women with the GSTM1 null genotype or with both GSTM1 and GSTT1 null genotypes ${ }^{(26)}$.

Our finding of a negative association between maternal exposure to $\mathrm{Hg}$ during pregnancy and birth weight is in accordance with a study from a birth cohort in Spain, where high cord blood THg concentrations were inversely related with birth weight ${ }^{(24)}$. In the Spanish study, infants in the highest quartile of cord blood THg weighed on average $143.7 \mathrm{~g}$ less $(95 \% \mathrm{CI}-251.8 \mathrm{~g},-35.6 \mathrm{~g})$ than those in the first quartile, adjusted for intake of fish and seafood. That study also indicated a possible increasing risk of delivering SGA babies with increasing THg, but the result was not statistically significant ${ }^{(24)}$. In most studies where no association between $\mathrm{Hg}$ exposure and birth weight is found, lack of adjustment for fish and seafood intake in the analysis may result in underestimation of both the toxicity of $\mathrm{Hg}$ and the nutritional benefits of eating fish products ${ }^{(52-54)}$.

There is a general concern that the benefits of fish and other seafood consumption may be offset by the concomitant presence of environmental contaminants. Contaminants that have been studied include dioxins and PCB and these contaminants are found to be associated with lower birth weight ${ }^{(55)}$. The effect of prenatal lowlevel PCB exposure on birth weight is assumed to be low ${ }^{(56)}$. A Belgian study by Sioen $e t$ al. $^{(57)}$ found that to meet the daily recommendations for PUFA through seafood consumption one would have to consume fatty fish twice weekly or vary between lean and fatty fish minimally three times weekly. At this level of seafood consumption they concluded that $\mathrm{Hg}$ exposure is below levels of toxicological concern, while for the dioxin-like compounds the TWI was reached. In Norway, low exposure to dioxins/PCB and $\mathrm{Hg}$ have been reported ${ }^{(39,58)}$. Whether PCB exposure interacts with the association between lower birth weight and $\mathrm{Hg}$ exposure may be addressed in future investigation.

We found that about $12 \%$ of the $\mathrm{Hg}$ exposures were from other sources than seafood, with $9 \%$ coming from eggs and cereals. Fishmeal is used as a source of protein for poultry and pigs and may be a source of $\mathrm{Hg}$ in addition to fish. Hg can also occur as residues in food (mainly as $\mathrm{IHg}$ ) due to their presence in the environment, as a result of human activities such as farming, industry or motor traffic. Contamination during food processing and storage are also possibilities.

The strength of the present study was that it is a large population-based study of pregnant women where food intake was reported during the first part of pregnancy. The potential influence of self-selection is a general concern in cohort studies and has been extensively explored in $\mathrm{MoBa}^{(59)}$. Comparison of several exposuredisease associations in $\mathrm{MoBa}$ with registry data for all births in Norway showed that the associations were not biased. The exposure to $\mathrm{Hg}$ is based on calculations using national data on THg concentrations in food data ${ }^{(37)}$. Calculations of the amount of seafood consumed were performed with use of a validated FFQ designed to capture the consumption of a range of seafood items ${ }^{(38)}$. Most other studies which have investigated neonatal Hg exposure have been performed in communities with very high fish consumption, while the participants in the present study have a more moderate fish intake. The weakness of our study is the lack of biological markers. Analyses done by measuring biomarkers, such as the concentrations of $\mathrm{THg}$ in blood or hair, are regarded as more accurate measures of exposure than assessments based on dietary data. Estimated $\mathrm{Hg}$ intake based on data from an FFQ was shown to be significantly associated with THg concentrations in maternal blood and hair in a Japanese study ${ }^{(60)}$. Estimated $\mathrm{Hg}$ values may involve uncertainties, but the FFQ appears to be a valid tool for assessment of exposure to $\mathrm{Hg}$. The main uncertainty in the data is that $\mathrm{Hg}$ concentrations in fish and seafood vary with type of species, the size of the fish and location of $\mathrm{catch}^{(8)}$. However, in the Norwegian Fish and Game study a comparison of estimated dietary exposure of MeHg calculated by the same FFQ as used in our study did show a strong association with THg measured in blood ${ }^{(39)}$. Furthermore, individual genetic and metabolic variation may influence the absorption and excretion of $\mathrm{Hg}^{(49,50)}$. 
In an attempt to overcome the dependence of $\mathrm{Hg}$ exposure on seafood intake, we analysed the impact of $\mathrm{Hg}$ exposure per gram of total seafood intake (see online supplementary material, Supplementary Table 1). A significant effect on birth weight was still seen for $\mathrm{Hg}$ exposure although weakened (26g compared with $34 \mathrm{~g}$ lower birth weight between the lowest and the highest quintile of $\mathrm{Hg}$ exposure). This finding is in accordance with the results from the analysis of the exposure measured as $\mathrm{Hg} \mu \mathrm{g} / \mathrm{kg} \mathrm{BW}$ per week.

\section{Conclusion}

While maternal seafood consumption has an overall positive association with infant birth weight, seafood also contributes to the dietary $\mathrm{Hg}$ exposure. The present study suggests that women in the highest range of $\mathrm{Hg}$ exposure have an increased risk of giving birth to SGA babies. A negative association between dietary $\mathrm{Hg}$ exposure and birth weight was observed within strata of seafood consumption, but the clinical impact of this is not clear. It is important to bear in mind that there is an overall positive association between seafood intake and birth weight in the present cohort. This would in itself suggest that the benefits of fish consumption are outweighing the risks from contaminant exposure at present concentrations in this population; although this would need to be confirmed with biological data. Dietary $\mathrm{Hg}$ exposure in women of childbearing age is of public health concern and needs to be monitored on a regular basis. Dietary recommendations need to focus on a balance between promoting fish and seafood as part of a balanced diet, while at the same time contain advice for restricting the intake of species and items with known high $\mathrm{Hg}$ concentrations.

\section{Acknowledgements}

Sources of funding: The Norwegian Mother and Child Cohort Study is supported by the Norwegian Ministry of Health and the Ministry of Education and Research, and the National Institute of Environmental Health Science (contract no. N01-ES-75558) and the National Institute of Neurological Disorders and Stroke (grant no. 1 UO1 NS 047537-01 and grant no. 2 UO1 NS 047537-06A1) of the US National Institutes of Health (NIH). The Norwegian Ministry of Health and the Ministry of Education and Research and the NIH had no role in the design, analysis or writing of this article. Conflicts of interest: The authors declare they have no actual or competing financial interests. Authors' contributions: The work presented here was carried out in collaboration between all authors. K.V., M.H., P.M. and A.L.B. defined the design and research theme. K.V., M.H. and A.L.B. analysed the data, interpreted the results and wrote the paper. H.K.K., J.A. and P.M. discussed analyses and interpreted the results.
H.K.K. and H.E.K. co-worked on associated data collection and their interpretation. All authors have contributed to, seen and approved the manuscript. Acknowledgements: The authors are grateful to all the participating families in Norway who take part in this ongoing cohort study.

\section{Supplementary material}

To view supplementary material for this article, please visit http://dx.doi.org/10.1017/S1368980013002619

\section{References}

1. Myers GJ, Davidson PW \& Shamlaye CF (1998) A review of methylmercury and child development. Neurotoxicology 19, 313-328.

2. Newland MC, Paletz EM \& Reed MN (2008) Methylmercury and nutrition: adult effects of fetal exposure in experimental models. Neurotoxicology 29, 783-801.

3. Clarkson TW \& Magos L (2006) The toxicology of mercury and its chemical compounds. Crit Rev Toxicol 36, 609-662.

4. Francesconi KA (2007) Toxic metal species and food regulations - making a healthy choice. Analyst 132, 17-20.

5. Rose M, Baxter M, Brereton N et al. (2010) Dietary exposure to metals and other elements in the 2006 UK Total Diet Study and some trends over the last 30 years. Food Addit Contam Part A Chem Anal Control Expo Risk Assess 27, 1380-1404.

6. Clemens S, Monperrus M, Donard OF et al. (2011) Mercury speciation analysis in seafood by species-specific isotope dilution: method validation and occurrence data. Anal Bioanal Chem 401, 2699-2711.

7. Sanzo JM, Dorronsoro M, Amiano P et al. (2001) Estimation and validation of mercury intake associated with fish consumption in an EPIC cohort of Spain. Public Health Nutr 4, 981-988.

8. Mahaffey KR, Clickner RP \& Jeffries RA (2009) Adult women's blood mercury concentrations vary regionally in the United States: association with patterns of fish consumption (NHANES 1999-2004). Environ Health Perspect 117, 47-53.

9. Storelli MM \& Marcotrigiano GO (2000) Fish for human consumption: risk of contamination by mercury. Food Addit Contam 17, 1007-1011.

10. European Food Safety Authority (2012) Scientific Opinion on the Risk for Public Health Related to the Presence of Mercury and Methylmercury in Food. Parma: EFSA.

11. Ballatori N \& Clarkson TW (1985) Biliary secretion of glutathione and of glutathione-metal complexes. Fundam Appl Toxicol 5, 816-831.

12. Hibbeln JR, Davis JM, Steer C et al. (2007) Maternal seafood consumption in pregnancy and neurodevelopmental outcomes in childhood (ALSPAC study): an observational cohort study. Lancet 369, 578-585.

13. Thorsdottir I, Birgisdottir BE, Halldorsdottir S et al. (2004) Association of fish and fish liver oil intake in pregnancy with infant size at birth among women of normal weight before pregnancy in a fishing community. Am J Epidemiol 160, 460-465.

14. Helland IB, Smith L, Saarem K et al. (2003) Maternal supplementation with very-long-chain $n-3$ fatty acids during pregnancy and lactation augments children's IQ at 4 years of age. Pediatrics 111, e39-e 44 .

15. Campoy C, Escolano-Margarit MV, Anjos T et al. (2012) Omega 3 fatty acids on child growth, visual acuity and neurodevelopment. Br J Nutr 107, Suppl. 2, S85-S106. 
16. Makrides M, Smithers LG \& Gibson RA (2010) Role of longchain polyunsaturated fatty acids in neurodevelopment and growth. Nestle Nutr Workshop Ser Pediatr Program 65 , 123-133.

17. Barker DJ (1990) The fetal and infant origins of adult disease. BMJ 301, 1111.

18. Savitz DA, Hertz-Picciotto I, Poole C et al. (2002) Epidemiologic measures of the course and outcome of pregnancy. Epidemiol Rev 24, 91-101.

19. Magnus P, Irgens LM, Haug K et al. (2006) Cohort profile: the Norwegian Mother and Child Cohort Study (MoBa). Int J Epidemiol 35, 1146-1150.

20. Norwegian Institute of Public Health (2011) Yearly figures Medical Birth Registry of Norway. http://www.fhi.no/ dokumenter/2a92108f4f.pdf (accessed May 2013).

21. Brantsaeter AL, Birgisdottir BE, Meltzer HM et al. (2012) Maternal seafood consumption and infant birth weight, length and head circumference in the Norwegian Mother and Child Cohort Study. Br J Nutr 107, 436-444.

22. Olsen SF, Grandjean P, Weihe P et al. (1993) Frequency of seafood intake in pregnancy as a determinant of birth weight: evidence for a dose dependent relationship. J Epidemiol Community Health 47, 436-440.

23. Halldorsson TI, Meltzer HM, Thorsdottir I et al. (2007) Is high consumption of fatty fish during pregnancy a risk factor for fetal growth retardation? A study of 44,824 Danish pregnant women. Am J Epidemiol 166, 687-696.

24. Ramon R, Ballester F, Aguinagalde X et al. (2009) Fish consumption during pregnancy, prenatal mercury exposure, and anthropometric measures at birth in a prospective mother-infant cohort study in Spain. Am J Clin Nutr 90 , $1047-1055$.

25. Bjerregaard P \& Hansen JC (2000) Organochlorines and heavy metals in pregnant women from the Disko Bay area in Greenland. Sci Total Environ 245, 195-202

26. Lee BE, Hong YC, Park H et al. (2010) Interaction between GSTM1/GSTT1 polymorphism and blood mercury on birth weight. Environ Health Perspect 118, 437-443.

27. Drouillet-Pinard P, Huel G, Slama R et al. (2010) Prenatal mercury contamination: relationship with maternal seafood consumption during pregnancy and fetal growth in the 'EDEN mother-child' cohort. Br J Nutr 104, 1096-1100.

28. US Department of Health and Human Services \& US Environmental Protection Agency (2004) What You Need to Know About Mercury in Fish and Shellfish. EPA-823-R04-005. Washington, DC: DHHS and EPA.

29. Oken E \& Bellinger DC (2008) Fish consumption, methylmercury and child neurodevelopment. Curr Opin Pediatr 20, 178-183.

30. Welch AA, Lund E, Amiano P et al. (2002) Variability of fish consumption within the 10 European countries participationg in the European investigation into cancer and nutrition (EPIC) study. Public Health Nutr 5, $1273-1285$.

31. Norwegian Scientific Committee for Food Safety Ad Hoc Group (2007) A Comprehensive Assessment of Fish and Other Seafood in the Norwegian Diet. Oslo: Norwegian Scientific Committee for Food Safety.

32. Meltzer HM, Brantsaeter AL, Ydersbond TA et al. (2008) Methodological challenges when monitoring the diet of pregnant women in a large study: experiences from the Norwegian Mother and Child Cohort Study (MoBa). Matern Child Nutr 4, 14-27.

33. Irgens LM (2000) The Medical Birth Registry of Norway. Epidemiological research and surveillance throughout 30 years. Acta Obstet Gynecol Scand 79, 435-439.

34. Norwegian Institute of Public Health (2012) The Norwegian Mother and Child Cohort Study, Questionnaries. http://www.fhi.no/morbarn (accessed May 2013).
35. Lauritsen J (2005) FoodCalc. http://www.ibt.ku.dk/jesper/ foodcalc/ (accessed April 2012).

36. Norwegian Food Safety Authority (2005) The Norwegian Food Composition Table. Oslo: Norwegian Food Safety Authority.

37. Brantsaeter AL, Haugen M, Alexander J et al. (2008) Validity of a new food frequency questionnaire for pregnant women in the Norwegian Mother and Child Cohort Study (MoBa). Matern Child Nutr 4, 28-43.

38. Brantsaeter AL, Haugen M, Thomassen Y et al. (2010) Exploration of biomarkers for total fish intake in pregnant Norwegian women. Public Health Nutr 13, 54-62.

39. Jenssen MT, Brantsaeter AL, Haugen M et al. (2012) Dietary mercury exposure in a population with a wide range of fish consumption - self-capture of fish and regional differences are important determinants of mercury in blood. Sci Total Environ 439, 220-229.

40. Skjaerven R, Gjessing HK \& Bakketeig LS (2000) Birthweight by gestational age in Norway. Acta Obstet Gynecol Scand 79, 440-449.

41. Haugen M, Brantsæter AL, Trogstad L et al. (2009) Vitamin D supplementation and reduced risk of preeclampsia in nulliparous women. Epidemiology 20, 270-276.

42. World Health Organization, International Programme on Chemical Safety (1990) IPCS Environmental Health Criteria 101: Methylmercury. Geneva: WHO.

43. US Environmental Protection Agency, Integrated Risk Information System (2001) Methylmercury (MeHg) (CASRN 22967-92-6). http://www.epa.gov/iris/subst/0073.htm (accessed May 2013)

44. Bjornberg KA, Vahter M, Grawe KP et al. (2005) Methyl mercury exposure in Swedish women with high fish consumption. Sci Total Environ 341, 45-52.

45. Schober SE, Sinks TH, Jones RL et al. (2003) Blood mercury levels in US children and women of childbearing age, 1999-2000. JAMA 289, 1667-1674.

46. Grandjean P, Bjerve KS, Weihe P et al. (2001) Birthweight in a fishing community: significance of essential fatty acids and marine food contaminants. Int $J$ Epidemiol 30, $1272-1278$.

47. Lucas M, Dewailly E, Muckle G et al. (2004) Gestational age and birth weight in relation to $n$ - 3 fatty acids among Inuit (Canada). Lipids 39, 617-626.

48. Ribas-Fito N, Sala M, Cardo E et al. (2002) Association of hexachlorobenzene and other organochlorine compounds with anthropometric measures at birth. Pediatr Res $\mathbf{5 2}$, 163-167.

49. Sagiv SK, Tolbert PE, Altshul LM et al. (2007) Organochlorine exposures during pregnancy and infant size at birth. Epidemiology 18, 120-129.

50. Karagas MR, Choi AL, Oken E et al. (2012) Evidence on the human health effects of low-level methylmercury exposure. Environ Health Perspect 120, 799-806.

51. Schlawicke EK, Stromberg U, Lundh T et al. (2008) Genetic variation in glutathione-related genes and body burden of methylmercury. Environ Health Perspect 116, 734-739.

52. Choi AL, Cordier S, Weihe $\mathrm{P}$ et al. (2008) Negative confounding in the evaluation of toxicity: the case of methylmercury in fish and seafood. Crit Rev Toxicol 38, 877-893.

53. Gochfeld M \& Burger J (2005) Good fish/bad fish: a composite benefit-risk by dose curve. Neurotoxicology 26, 511-520.

54. Budtz-Jorgensen E, Grandjean P \& Weihe P (2007) Separation of risks and benefits of seafood intake. Environ Health Perspect 115, 323-327.

55. Guo YL, Lambert GH \& Hsu CC (1995) Growth abnormalities in the population exposed in utero and early postnatally to polychlorinated biphenyls and dibenzofurans. Environ Health Perspect 103, Suppl. 6, 117-122. 
56. Sagiv SK, Tolbert PE, Altshul LM et al. (2007) Organochlorine exposures during pregnancy and infant size at birth. Epidemiology 18, 120-129.

57. Sioen I, De Henauw S, Van Camp J et al. (2009) Comparison of the nutritional-toxicological conflict related to seafood consumption in different regions worldwide. Regul Toxicol Pharmacol 55, 219-228.

58. Caspersen IH, Knutsen HK, Brantsæter AL et al. (2013) Dietary exposure to dioxins and PCBs in a large cohort of pregnant women: results from the Norwegian Mother and Child Cohort Study (MoBa). Environ Int 59, 398-407.

59. Nilsen RM, Vollset SE, Gjessing HK et al. (2009) Selfselection and bias in a large prospective pregnancy cohort in Norway. Paediatr Perinat Epidemiol 23, 597-608.

60. Yaginuma-Sakurai K, Shimada M, Ohba T et al. (2009) Assessment of exposure to methylmercury in pregnant Japanese women by FFQ. Public Health Nutr 12, $2352-2358$. 